\title{
Inhibition of Steroid Receptor Coactivator-1 Blocks Estrogen and Androgen Action on Male Sex Behavior and Associated Brain Plasticity
}

\author{
Thierry D. Charlier, ${ }^{1}$ Gregory F. Ball, ${ }^{2}$ and Jacques Balthazart ${ }^{1}$ \\ ${ }^{1}$ Center for Cellular and Molecular Neurobiology, Research Group in Behavioral Neuroendocrinology, University of Liège, B-4020 Liège, Belgium, and \\ ${ }^{2}$ Department of Psychological and Brain Sciences, Johns Hopkins University, Baltimore, Maryland 21218
}

\begin{abstract}
Studies of eukaryotic gene expression demonstrate the importance of nuclear steroid receptor coactivators in mediating efficient gene transcription. However, little is known about the physiological role of these coactivators in vivo. In Japanese quail, the steroid receptor coactivator-1 (SRC-1) is broadly expressed in steroid-sensitive brain areas that control the expression of male copulatory behavior, and we investigated the role of this coactivator by antisense technology. Daily intracerebroventricular injections of locked nucleic acid (LNA) antisense (AS) oligonucleotides targeting SRC-1 significantly reduced the expression of androgen- and estrogen-dependent male-typical sexual behaviors compared with control animals that received the vehicle alone or scrambled oligonucleotides. Sexual behavior was restored and even enhanced within $48 \mathrm{~h}$ after interruption of LNA injections. Western blot analysis confirmed the decrease of SRC-1 expression in AS animals and suggested an overexpression $48 \mathrm{~h}$ after the end of injections. The effects of SRC-1 knock-down on behavior correlated with a reduction in volume of the preoptic medial nucleus (POM) when its borders were defined by Nissl staining or by aromatase immunohistochemistry. The amount of aromatase-immunoreactive material in POM was also reduced in the AS compared with the control group. Previous work on SRC-1 knock-out mice raised questions about the importance of this specific coactivator in the regulation of reproductive behavior and development of sexually dimorphic structures in the CNS. Together, the present findings indicate that SRC-1 modulates steroid-dependent gene transcription and behavior and highlight the rapid time course of steroid-induced brain plasticity in adult quail.
\end{abstract}

Key words: preoptic area; aromatase; vasotocin; sexually dimorphic nucleus; antisense; Japanese quail

\section{Introduction}

It is now clear that a suite of proteins are needed for the physiological action of steroid hormones, including their actions on brain and behavior. For example, in many species, testosterone must be converted to an estrogenic metabolite via the enzyme aromatase to be effective in the activation of male-typical sexual behavior, and variation in the activity of this enzyme has been useful in predicting the behavioral effectiveness of testosterone (Dessi-Fulgheri et al., 1976; Balthazart et al., 2004). A recently identified family of proteins known as nuclear coactivators and corepressors has been found to be essential for the transcriptional efficiency of steroid receptors (McKenna et al., 1999; McKenna and O'Malley, 2002). Cofactors such as CREB (cAMP response element-binding protein)-binding protein (CBP) and steroid re-

Received Aug. 27, 2004; revised Dec. 2, 2004; accepted Dec. 9, 2004.

This research was supported by National Institute of Mental Health Grant MH50388 (G.F.B. and J.B.), Belgian Fonds de la Recherche Fondamentale Collective Grant 2.4555 .01 (J.B.), French Community of Belgium Grant ARC 99/04-241 (J.B.), and the University of Liège (Fonds Spéciaux pour la Recherche) (J.B.). T.D.C. is a Fonds pour la Formation à la Recherche dans I'Industrie et dans I'Agriculture grant recipient.

Correspondence should be addressed to Thierry D. Charlier, Center for Cellular and Molecular Neurobiology, Research Group in Behavioral Neuroendocrinology, University of Liège, 17 place Delcour (Batiment L1), B-4020 Liège, Belgium. E-mail: thierry.charlier@student.ulg.ac.be.

DOI:10.1523/JNEUROSCI.3533-04.2005

Copyright $\odot 2005$ Society for Neuroscience $\quad$ 0270-6474/05/250906-08\$15.00/0 ceptor coactivator-1 (SRC-1) are widely distributed in the mammalian (Misiti et al., 1998; Meijer et al., 2000) and avian (Auger et al., 2002; Charlier et al., 2002) brain. These coactivators are enriched in brain areas that express sex steroid hormones receptors and are involved in the hormonal activation of reproductive behaviors. However, little is known about the importance of these proteins for behavioral actions of steroids in the brain. These proteins could potentially explain variation in the behavioral effectiveness of steroid hormones.

SRC-1 is necessary for the estrogenic defeminization of sexual behavior in male rats and the masculinizing effects of estrogen on the volume of the sexually dimorphic nucleus of the preoptic region (Auger et al., 2000). SRC-1 may also play a role in the estrogenic activation of female sexual behaviors (Molenda et al., 2002). Studies with SRC-1 knock-out mice found no significant effects on female sexual responding, but it was demonstrated that developmental compensation had occurred based on the upregulation of other coactivators (Apostolakis et al., 2002). We wanted to establish whether SRC-1 is necessary for the behavioral activation by testosterone of male-typical sexual responding in adult animals and for the associated neural changes that are regulated by this steroid. We conducted our studies with Japanese quail in which clearly showed that testosterone acting via estrogenic and androgenic metabolites in the medial preoptic nucleus (POM) is 
necessary and sufficient for the activation of male behavioral responses and that the steroid has effects on the volume of the POM and on aromatase- and vasotocin-immunoreactive structures (Balthazart et al., 1996b). We used antisense (AS) oligonucleotides to produce a gene knock-down of SRC-1 and found that we could successfully reduce the expression of the SRC-1 protein in the POM, which resulted in dramatic effects on the activation of both androgen- and estrogen-dependent male-typical sexual behaviors, on the size of the POM, and on the expression of the aromatase and vasotocin proteins. Based on these findings, this cofactor is clearly essential for androgen and estrogen regulation of male-typical sexual behaviors, brain plasticity, and related proteins. These studies also illustrate the surprisingly rapid time course (within $2 \mathrm{~d}$ ) of steroid effects on the volume of the sexually dimorphic preoptic medial nucleus in adult quail.

\section{Materials and Methods}

Animals and in vivo treatments. Two successive experiments based on similar protocols were performed with a total of 40 male Japanese quail (Coturnix japonica) that were purchased at the age of $\sim 3$ weeks from a local breeder in Belgium. All experimental procedures were approved by the Ethical Committee for the Use of Animals at the University of Liège.

Within 1 week after their arrival in the laboratory, all males were castrated as described previously (Schumacher and Balthazart, 1984). Two weeks later, they were implanted with a chronic injection cannula in the third ventricle to allow for the central administration of oligodeoxynucleotide (ODN) (for details of the procedure, see Castagna et al., 1998) (coordinates of the cannula tip were $5.10 \mathrm{~mm}$ anterior, $2.35 \mathrm{~mm}$ above, and $0.00 \mathrm{~mm}$ lateral to the center of the interaural axis). The location of the cannula in the ventricle was confirmed at the time of implantation and before every injection of ODN by the fact that a small drop of CSF leaked out of the injection cannula when the dummy insert cannula was removed and before the injection cannula was connected to the injector. Animals were then housed in isolation and allowed to recover for at least 2 weeks. One day before the first the injection, the birds were behaviorally tested in the presence of a sexually mature female for 5 min (for details of the procedure, see below). All subjects were sexually inactive, which confirmed the effects of castration.

Birds were then injected daily with $1 \mu \mathrm{g}$ of AS ODN, $1 \mu \mathrm{g}$ of scrambled ODN (SC), or vehicle as controls. We used the third generation antisense ODN, a chimer consisting of locked nucleic acid (LNA) (Koshkin et al., 1998; Singh et al., 1998) and deoxyribonucleotides (LNA/DNA/LNA gap-mer) purchased from Proligo (Paris, France). The very high affinity of LNA-containing oligonucleotides for their complementary target RNA, the acceleration of RNase $\mathrm{H}$ activity [a fact still disputed in the brain, because RNase $\mathrm{H}$ might not be present in this tissue (Sawai et al., 1977; Landgraf et al., 1997)], and their stability in biological media make these chimers a very convenient tool to regulate gene expression through RNA targeting (Braasch and Corey, 2001; Kurreck et al., 2002). The sequence for the 19-mer antisense spanning the putative start codon of the quail SRC- 1 was $5^{\prime}$-CAAGgccactcatgtTGAC- 3 ' (the LNA monomers are represented by uppercase letters and DNA monomers by lowercase letters), and the scrambled control ODN was 5'-CAGAgccactactgtGTAC- $3^{\prime}$. ODN were dissolved in sterile saline $(1 \mu \mathrm{g} / \mu \mathrm{l}$ in $\mathrm{NaCl} 0.9 \%)$. A basic local alignment search tool (BLAST) search was performed on the National Center for Biotechnology website (http://www.ncbi.nlm.nih.gov/BLAST/) to confirm that both antisense and scrambled sequences were not complementary to any other known sequence.

Eight hours after the first injection, birds were pretested again for behavior (see procedure below) to check for gross behavioral effects of the LNA. We did not detect any major qualitative effect of the injection (AS, SC, or vehicle) on the general activity, as attested by normal social but not sexual interactions with females, general mobility, and the presence of an intense preening. Throughout the experiment, the birds treated with antisense ODN also consumed food at a normal rate, as noted by the fact that their feeders were emptied at the same rate as in control birds and that no difference in body mass was ever observed.
After the third day of injection, one 20-mm-long SILASTIC tube (1.57 $\mathrm{mm}$ inner diameter, $2.41 \mathrm{~mm}$ outer diameter; Silclear Tubing; Degania Silicone, DeganiaBet, Israel) filled with crystalline testosterone (Sigma, St. Louis, MO) was implanted subcutaneously in the neck region. These implants restore the minimal level of steroid required by the male quail to exhibit full copulatory behavior (Balthazart et al., 1983). Moreover, it is well established that steroids diffuse through SILASTIC implant at relatively constant rate and establish stable levels of plasma testosterone for periods of at least 6 weeks in quail (Dziuk and Cook, 1966; Stratton et al., 1973; Desjardins and Turek, 1977). Animals were tested then in the presence of a sexually mature female for $5 \mathrm{~min}$ every day for $7 \mathrm{~d}$. The behavioral test started $\sim 8 \mathrm{~h}$ after the stereotaxic injection. During these tests, sexual behavior patterns including neck grab (NG), mount attempt (MA), mount (M), cloacal contact movement (CCM), as well as strut and crow (for a detailed description of these behaviors, see Adkins and Adler, 1972) were quantified by an observer blind of the treatment of the birds. At the end of the experiment, the birds had thus been injected 11 times with ODN and tested seven times for sexual behavior. After the last behavioral test, animals were weighed, and the cloacal gland area was measured with calipers. The cloacal gland area represents a very sensitive index of androgenic stimulation (Sachs, 1967; Delville et al., 1984). Eight hours after the last injection, the birds were killed by decapitation, and brains were processed for histology and protein analysis. All subjects were, at that time, checked for the presence of the SILASTIC implants and completeness of castration. Three males were removed from the data analysis because of various problems identified at that time. All numbers of subjects presented below represent males that were in the desired endocrine condition.

Tissue processing and staining. Brains were dissected out of the skull and separated into two halves by a midsagittal cut passing through the third ventricle. The right half of the brain was fixed in 5\% acroleine in $0.01 \mathrm{PBS}, \mathrm{pH} 7.3$, for $3 \mathrm{~h}$, washed extensively, and cryoprotected overnight in $30 \%$ sucrose before freezing on dry ice. The preoptic region was dissected out of the left half of the brain and directly frozen on dry ice. The samples were kept at $-80^{\circ} \mathrm{C}$ until used.

Thirty-micrometer-thick coronal sections were cut on a cryostat starting at the rostral end of the acrolein-fixed brain. The plane of the sections was adjusted to match as closely as possible the plane of the quail brain atlas (Baylé et al., 1974). Sections located between the tractus septomesencephalicus and the locus ceruleus were collected in $0.05 \mathrm{M}$ Trisbuffered saline $[0.05 \mathrm{~m}$ Tris buffer containing $0.125 \mathrm{M} \mathrm{NaCl}$, pH 7.6 (TBS)] in four sets and stored in a cryoprotectant solution ( $0.05 \mathrm{M} \mathrm{PBS,}$ $1 \%$ polyvinyl pyrolidone, $30 \%$ sucrose, and $30 \%$ ethylene glycol) at $-20^{\circ} \mathrm{C}$ until used. Sections were then stained either for Nissl bodies or for aromatase or vasotocin by immunohistochemistry (for procedures, see Foidart et al., 1995; Absil et al., 2002a, respectively). The vasotocin and aromatase immunoreactivity in the POM, as well as the volume of this nucleus as defined by Nissl staining, have been shown to depend on the synergistic action of androgens and estrogens and to be causally related to the expression of male sexual behavior (Panzica et al., 1987; Balthazart et al., 1996a; Aste et al., 1998; Panzica et al., 2001; Viglietti-Panzica et al., 2001). These proteins are therefore excellent markers to study the potential modulation of steroid activity in this brain region.

Image analysis. Quantification was performed by an observer blind to the treatments on images digitized through a CCD camera (XC-77CE; Sony, Tokyo, Japan) attached to a microscope and connected to a MacIntosh computer with the help of NIH Image software (version 1.62; Wayne Rasband, National Institutes of Health, Bethesda, MD). The POM volume was measured in the aromatase- and Nissl-stained sections. All sections containing the nucleus throughout its rostrocaudal extent were digitized, and the area of the nucleus was traced and measured. Areas were summed and multiplied by the sampling interval to derive an estimate of the volume. The percentage of surface covered by vasotocin- or aromatase-immunoreactive structures (equaling the fractional area) was also measured with NIH Image 1.62.

We also calculated the integrated optical density (IOD) of the aromatase in the POM reflecting the aromatase content in the nucleus (Roselli et al., 2004). This was defined as the relative optical density of the aromatase immunoreactivity multiplied by the fractional area covered by 
the signal within the nucleus and by the total POM volume. The optical density was measured with the NIH Image program (previously calibrated in standardized optical densities) on the whole surface of the POM at the level of the anterior commissure. The relative optical density was defined as the ratio of the density measured within the POM to the density measured in an adjacent area containing no aromatase.

Western blotting analysis. The fresh frozen preoptic regions were homogenized in ice-cold lysis buffer $(50 \mathrm{~mm}$ Tris $\mathrm{HCl}, \mathrm{pH}$ 7.2, $0.1 \mathrm{~mm}$ EDTA, $0.1 \%$ Nonidet P- $40,5 \mathrm{~mm} N$-ethyl-maleimide, and one tablet of complete protease inhibitor; Boehringer Mannheim, Indianapolis, IN) and centrifuged at $2000 \times g$ for $15 \mathrm{~min}$ at $4^{\circ} \mathrm{C}$. The protein content in the supernatant was measured by the Micro BCA Protein Assay (Pierce, Rockford, IL).

Proteins $(10 \mu \mathrm{g} /$ lane $)$ in the extracts were separated by electrophoresis on SDS/polyacrylamide gels (8\%) and transferred to polyvinylidene difluoride membranes (Amersham Biosciences, Uppsala, Sweden) using the Bio-Rad (Hercules, CA) miniprotean II electrophoresis system and a semidry transfer unit (Laemmli, 1970). The membranes were treated for $2 \mathrm{~h}$ in blocking buffer (5\% nonfat dry milk in TBS) and incubated overnight at $4^{\circ} \mathrm{C}$ with the primary antibody to SRC-1 (1:1000; catalog \#PA1840; Affinity BioReagents, Golden, CO). The primary antibody was visualized with a secondary goat antibody coupled to horseradish peroxidase (1:1000; Amersham Biosciences), and the peroxidase activity was revealed with the enhanced chemiluminescence system (ECL; Amersham Biosciences). The membranes were then stripped, extensively rinsed, and incubated for $1 \mathrm{~h}$ at room temperature with a monoclonal $\beta$-actin antibody (1:10,000; clone AC-74; Sigma) that was subsequently visualized as described above. The optical density after ECL detection was measured by image analysis with NIH Image 1.62. The effective optical density was calculated as the ratio of the optical density of the band to the optical density measured just below that band. The final results were expressed as the ratio of the effective optical density of the SRC- 1 band normalized with the effective optical density of $\beta$-actin.

Data analysis. Behavioral data were analyzed by mixed two-way ANOVA with one independent factor (experimental groups) and one repeated factor (the successive behavioral tests), followed when appropriate by post hoc Tukey's tests. Results obtained by histology and protein analysis were analyzed by Student's $t$ tests or one-way ANOVAs. Behavioral data, fractional areas covered by vasotocin, and SRC-1 measures in Western blots were transformed to $\log (x+1)$ to normalize distributions. ANOVAs were followed when appropriate by post hoc Fisher's protected least significant difference (PLSD) tests. Differences were considered significant for $p<0.05$.

\section{Results}

\section{Experiment 1}

The first experiment included a total of nine males: four were injected with the antisense LNA (AS group), and the other five control males were injected with the scrambled ODN (SC group). The complete male-typical copulatory sequence (NG to CCM) was observed in control males after treatment with testosterone, but these behaviors were markedly inhibited in males injected with LNA antisense. The frequencies of CCM and strut, an androgen-dependent precopulatory and postcopulatory display, in the two groups are illustrated in Figure $1 A$. The frequency of other behavioral patterns in the copulatory sequence varied in a manner that is similar to CCM, and these data are thus not presented in detail to avoid redundancy.

The AS and SC birds exhibited no sexual behavior during the pretest and the first day after testosterone implantation. Maletypical behaviors were then observed with progressively increasing frequencies starting on the second day after testosterone implantation in both groups but to a greater degree in SC than in AS birds. A mixed-design two-way ANOVA revealed a significant main effect of antisense injections on all aspects of copulatory behavior except $\mathrm{NG}\left(\mathrm{NG}, F_{(1,7)}=4.537, p=0.0707\right.$; $\mathrm{MA}, F_{(1,7)}=$ 5.867, $p=0.0459 ; \mathrm{M}, F_{(1,7)}=7.807, p=0.0267 ; \mathrm{CCM}, F_{(1,7)}=$

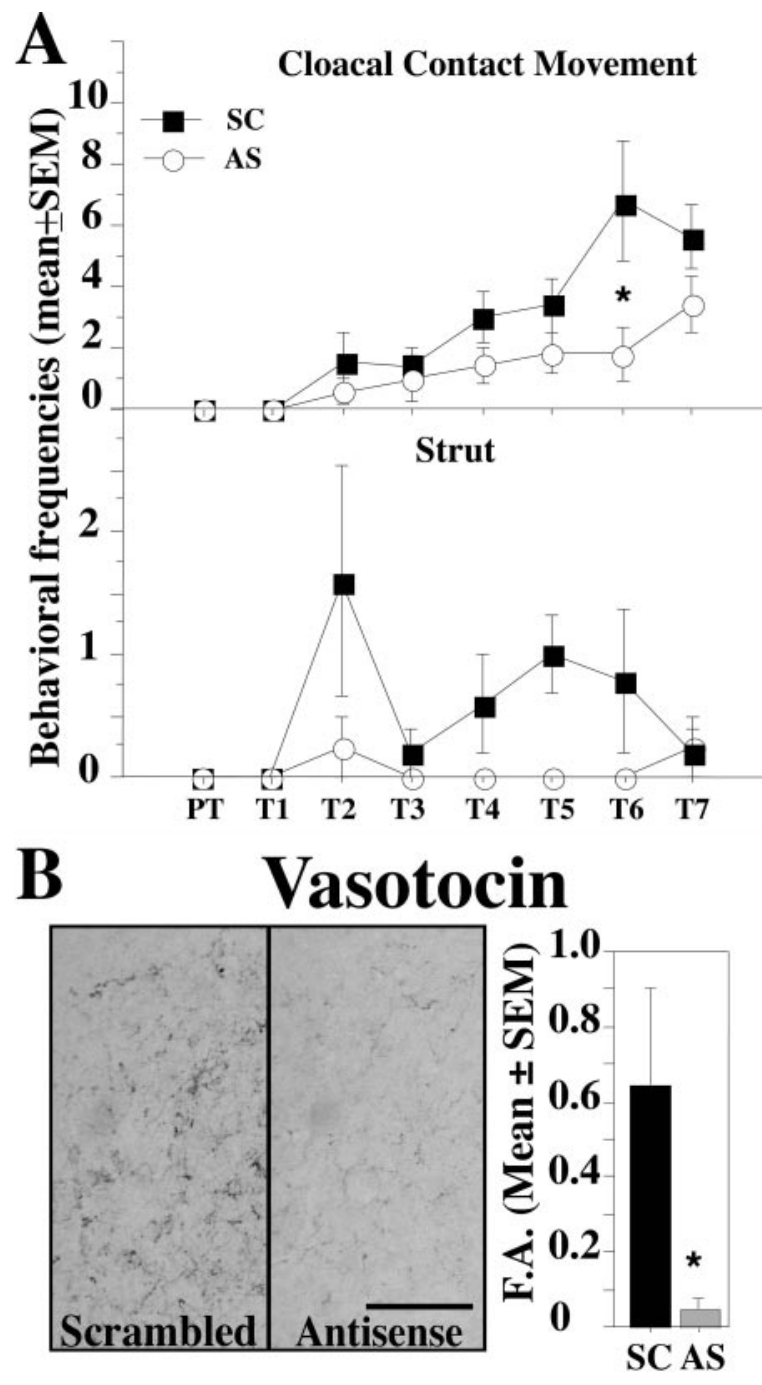

Figure 1. Inhibitory effects of SRC-1 expression downregulation on testosterone-dependent male sexual behavior and vasotocin innervation of the preoptic area. A, Cloacal contact movement and strut frequencies observed during the pretest (PT) and the following seven tests (T1-T7) in the SC-and AS-injected subjects. B, Vasotocinergic innervation of the POM in SC- and AS-injected subjects. Scale bar, $50 \mu \mathrm{m}$. The bar graph represents the percentage of surface covered by vasotocin-immunoreactive structures in P0M [fractional area (F.A.)]. ${ }^{*} p<0.05$ versus SC on the corresponding day.

$7.632, p=0.0280)$. As expected, trials also had a significant effect on all behaviors $(p<0.0001)$. The interaction between these two factors was not significant $(p \leq 0.0871)$. The injection of LNA antisense also significantly inhibited the strutting displays $\left(F_{(1,7)}\right.$ $=6.486 ; p=0.0383)$ but not the crowing frequency $\left(F_{(1,7)}=\right.$ 2.393; $p=0.1658$ ), but this behavior was rarely observed during the tests in the presence of a female (AS males never crowed, one SC male crowed during each test, and two crowed sporadically).

The volume of the POM as identified by the cluster of aromatase-immunoreactive cells was numerically smaller in the AS compared with the SC group (SC, $0.244 \pm 0.018 \mathrm{~mm}^{3}, n=3$; AS, $0.196 \pm 0.017 \mathrm{~mm}^{3}, n=4$; all means \pm SEM), but this numerical difference, based on relatively small number of subjects, was not statistically significant $(t=1.882$; $\mathrm{df}=5 ; p=$ 0.1186 ). Repeated injections of SRC- 1 antisense dramatically decreased the vasotocin innervation of the POM, another well established steroid-dependent response. The fractional area covered by vasotocin-immunoreactive structures was significantly 
A
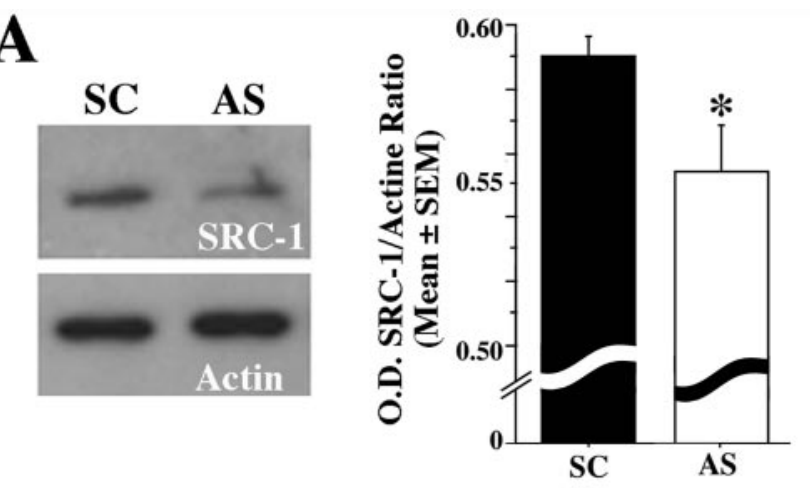

B
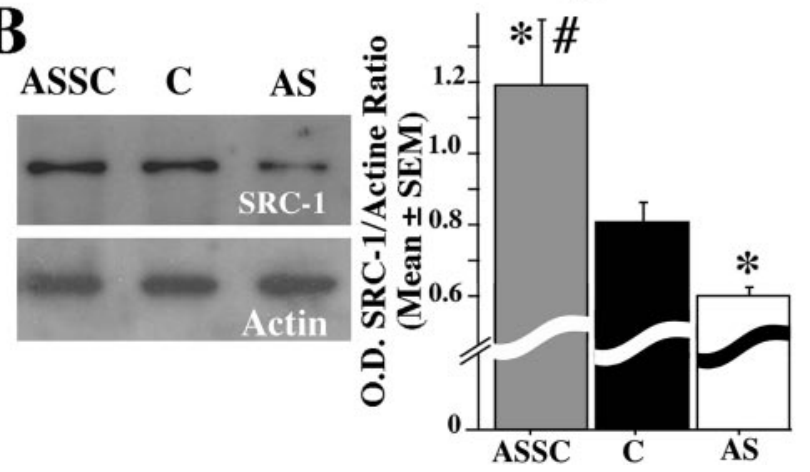

Figure 2. Representative Western blot (left) and corresponding optical density (0.D.) measures (right) in birds treated with SRC-1 AS or with SC ODN $(A)$ and in combined controls (C), AS birds, and ASSC birds $(B)$. The ordinate of the bar graphs is expressed as the ratio of the optical density of SRC- 1 normalized based on $\beta$-actin expression. ${ }^{*} p<0.05$ versus SC or C; $\# p<0.05$ versus AS.

lower in AS than in SC birds $(t=2.682 ; \mathrm{df}=5 ; p=0.0437$ ) (Fig. $1 B)$. The inhibitory effect of LNA antisense on SRC-1 expression as measured by the optical density of the corresponding band was confirmed by Western blot analysis $(t=2.450$; $\mathrm{df}=7$; $p=$ 0.0441) (Fig. 2A).

\section{Experiment 2}

A second experiment was performed to confirm these effects on a larger sample of birds and test the specificity of these effects with the addition of a second control group (injected with vehicle alone) and by testing whether males injected with antisense would recover a normal behavior and neural gene expression after antisense injections were discontinued. This experiment was performed on a total of 28 males: 13 were injected with antisense, seven with scrambled ODN, and eight with the injection vehicle only.

Statistical analyses ( $t$ tests) did not reveal any significant differences between the two control groups (scrambled and vehicle) for all behavioral-, neuroanatomical-, and neurochemicaldependent variables that were considered. This confirmed the lack of effects of the LNA injection by itself. To increase the power of the statistical analyses, results from the two control groups were then pooled in all subsequent analyses that are presented below.

As in the previous experiment, male-typical behaviors were observed with progressively increasing frequencies starting on the second or third day after testosterone implantation in control (label C) and to a lesser extent in antisense (label AS)-injected birds (Fig. 3). The changes in time of the frequency of all behavioral patterns in the copulatory sequence were very similar, and these data are thus not presented in detail to avoid redundancy

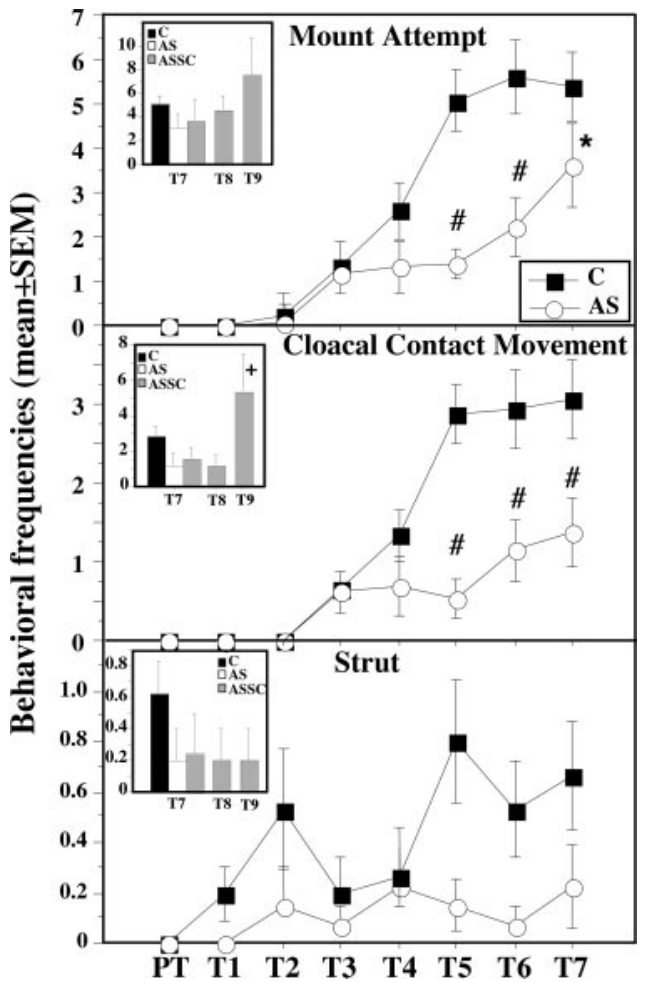

Figure 3. Inhibitory effects of SRC-1 expression downregulation on testosterone-dependent male sexual behavior in control (C)- and AS-injected subjects. Insets illustrate the behavioral recovery after cessation of antisense injections. The AS group was split into two groups after test 7 (T7). One was killed, and the other received SC (ASSC) injections and was behaviorally tested for $2 \mathrm{~d}$ (T8-T9). ${ }^{*} p<0.05$ versus SC; ${ }^{\#} p<0.01$ versus SC on the corresponding day; in the inset, ${ }^{+} p<0.05$ versus ASSC at T7. PT, Pretest.

(MA and CCM only are illustrated in Fig. 3). Analysis of these data by mixed-design two-way ANOVA revealed significant main effects of antisense injections on the frequencies of $\mathrm{NG}\left(F_{(1,26)}=\right.$ $11.301 ; p=0.0024), \mathrm{MA}\left(F_{(1,26)}=10.255 ; p=0.0036\right), \mathrm{M}\left(F_{(1,26)}=\right.$ $12.695 ; p=0.0014)$, and $\operatorname{CCM}\left(F_{(1,26)}=17.227 ; p=0.0003\right)$. These results are similar to those of experiment 1 , with the exception that the difference in NG frequency now became significant because of the much larger number of subjects that were used. As expected, trials also had a significant effect on all aspects of copulatory behavior (respectively, $F_{(6,156)}=41.775, F_{(6,156)}=$ $47.897, F_{(6,156)}=33.499$, and $F_{(6,156)}=33.456 ; p<0.0001$ in each case). The interaction between trials and groups was also significant for each behavior (all $p$ values $\leq 0.0003$ ). The repeated injection of LNA antisense also inhibited the display of struts (group difference, $F_{(1,26)}=4.416, p=0.0454$; trial effect, $F_{(6,156)}=2.858$, $p=0.0114$; interaction, $\left.F_{(6,156)}=1.244, p=0.2870\right)$.

All subjects were killed at the end of the behavioral testing for brain analysis, except for five birds from the AS group that were kept alive. For 2 additional days, they were injected with scrambled ODN to test whether they would be able to recover from the downregulation of SRC-1 (ASSC group). By the second day of the injection of the scrambled ODN [test 9 (T9)], the animals dramatically increased their behavioral response to testosterone. Their frequency of M and CCM on test 9 was significantly higher compared with the last test (T7) after antisense injection (paired $t$ test; $t=3.210$, df $=4, p=0.0326$; and $t=3.108$, df $=4, p=$ 0.0359 , respectively) (Fig. 3 , insets). Because of the relatively high variance, the increase in NG and MA frequency between T7 and T9 was not statistically significant, although a clear trend toward 
an increase of these behaviors could be observed (for an illustration of MA, see Fig. 3, inset). The frequency of MA and CCM in the ASSC birds on T9 was even higher (approximately double) than the frequencies observed on $\mathrm{T} 7$ in controls that seemed to have reached a plateau of behavioral activity for at least $3 \mathrm{~d}$.

No difference in body weight was observed between the four groups of birds at the end of the experiment, indicating a lack of general toxicity of these LNAs. In addition, the cloacal gland area in the four groups was similar, clearly demonstrating that the intracerebroventricular injections of antisense LNA did not result in peripheral effects on androgen-dependent structures.

Western blots confirmed the downregulation of SRC-1 expression in antisense-injected animals compared with the control (Fig. 2 B). Moreover, the ASSC group demonstrated a significantly stron-

ger expression of SRC-1 compared with the control subjects at the time when they were killed (comparison of the three groups, $F_{(2,16)}=10.780 ; p=0.0011$ ) (for results of post hoc Fisher's PLSD tests, see Fig. 2B). This increased expression of SRC-1 in ASSC birds is likely to have caused the major increase in behavioral frequencies because no changes in plasma testosterone were expected to occur during this short period (SILASTIC capsules release testosterone at a constant rate; see Materials and Methods). Previous work also indicates that, once castrated male quail treated with SILASTIC implants filled with testosterone have reached their maximal sexual activity, the frequencies of behaviors they express during repeated testing (up to 10 tests) remain stable for extended periods of at least 1 or 2 weeks (Balthazart et al., 1988, 1998; Dermon et al., 1999; Tlemçani et al., 2000; Absil et al., 2002b). Spontaneous changes in behavioral frequency of the magnitude detected here (doubling or more) were never observed in any of these studies. It is therefore unlikely that the very rapid increase observed here in the ASSC group was attributable to repeated testing. This interpretation should, however, be confirmed in future studies including a proper control group tested in parallel.

The behavioral inhibition induced by the blockade of SRC-1 expression was paralleled in the brain by major neuroanatomical and neurochemical changes (Fig. 4A). The POM volume as defined by Nissl staining was markedly decreased in subjects treated with the SRC-1 antisense compared with the control and the ASSC groups $\left(F_{(2,20)}=6.065 ; p=0.0087\right)$ (for details of post hoc tests, see Fig. $4 A$, top row, $B$ ). The ASSC group had a numerically larger POM volume than the control group, but the difference was not statistically significant.

In parallel, the volume of the POM defined by the cluster of aromatase-immunoreactive neurons was smaller in the AS group compared with the two other groups $\left(F_{(2,22)}=4.620\right.$; $p=0.0211$ ) (Fig. $4 A$, bottom row, $B$ ). In addition, the IOD of aromatase in the POM reflecting aromatase content in this nucleus was decreased in the AS compared with the control group (Fig. $4 B$, bottom). Moreover, this IOD was significantly higher in the ASSC group compared with the control group $\left(F_{(2,22)}=9.195 ; p=0.0013\right.$ ) (for post hoc tests, see Fig. $4 B$ ). It is noteworthy that the behavioral, neurochemical, and neuroana- tomical changes observed in the ASSC group compared with the AS group occurred in only $2 \mathrm{~d}$.

\section{Discussion}

We demonstrated here that injection of LNA antisense ODNs directed against the mRNA for SRC-1 results in a significant knock-down of the corresponding protein as measured by Western blots. This knock-down results in a profound inhibition of testosterone-dependent male sexual behaviors in Japanese quail. These effects of the ODNs seem to be limited to the brain given that no effect was observed on peripheral steroid-dependent responses, such as cloacal gland growth. In quail, it has been clearly established that some of these behaviors (e.g., crowing and strutting) are dependent on androgenic metabolites of testosterone, whereas others (e.g., neck grab, mounts, and CCM) are dependent on estrogenic metabolites (Adkins et al., 1980; Schumacher and Balthazart, 1983). The present results therefore support the notion that SRC-1 facilitates the transcriptional actions of both androgen and estrogen receptors on male-typical behaviors. Adult testosterone action also regulates male-biased sex differences in the volume of the POM in quail, as well as the number of cells expressing immunoreactive aromatase and immunoreactive fibers for the peptide vasotocin in this brain area. The antisense ODN treatment decreased the volume of this nucleus and the density of immunoreactivity of aromatase and vasotocin by $\sim 30 \%$ (Figs. 1, 4), a decrease that has approximately the same magnitude as the differences observed between intact males and females (Viglietti-Panzica et al., 1986; Balthazart et al., 1996a; Panzica et al., 2001). Sex differences in these neural attributes are also dependent on a synergy between androgenic and estrogenic metabolites of testosterone (Absil et al., 2001; Viglietti-Panzica et al., 2001). These data thus provide additional support for the conclusion that SRC-1 enhances the transcriptional action of ligand-activated androgen receptors and estrogen receptors.

Previous studies have indicated the importance of coactivators for the actions of estrogen on brain and behavior in female rodents during ontogeny and in adulthood (Auger et al., 2000; Molenda et al., 2002). In a previous study that investigated the actions of coactivators for adult sexual behaviors, both SRC-1 and $\mathrm{CBP}$ were blocked and only moderate effects were observed 
on the ability of estrogen to facilitate the lordosis response (intensity only), as well as to induce the expression of the progesterone receptor in female rats (Molenda et al., 2002). Another study, however, demonstrated a profound inhibition of lordosis in female rats treated with SRC-1 antisense (Apostolakis et al., 2002). Studies of SRC-1 knock-out mice also found no effect on the development of the androgen-dependent motoneurons within the spinal nucleus of the bulbocavernosus (Monks et al., 2003), suggesting that this cofactor may not be important for androgendependent neuroendocrine processes.

The present study clearly indicates that SRC-1 alone is important for the activational effects of testosterone on many aspects of male-typical sexual behaviors (Figs. $1 A, 3$ ), as well as for the maintenance of male-typical neural attributes such as POM volume and testosterone-dependent patterns of aromatase and vasotocin immunoreactivity (Figs. $1 B, 4$ ). In our study, we also assessed the recovery of male-typical behaviors and neural attributes in a subset of treated animals in which we ceased the administration of the antisense ODNs $2 \mathrm{~d}$ before behavioral testing and brain collection. In these animals, the behavioral measures (with the exception of struts) as well as the neural measures were similar or even greater than the control values. These findings indicate that the effects of the ODN treatment are reversible and therefore suggest that they do not result from some sort of generalized toxicity. The general health of the animals seemed to be unaffected by the treatment, as assessed by measures such as body mass and the development of androgen-dependent peripheral structures such as the cloacal gland, as well as by the qualitative assessment of the birds mobility and food consumption. The LNA method has rarely been used in vivo (but see Mong et al., 2003), but one study suggests that it should reduce toxic effects associated with other antisense techniques such as phosphorothioate ODNs (Wahlstedt et al., 2000). The magnitude of the effects observed here, their reversibility, and the lack of general toxic effects highlights the usefulness of this method for the manipulation of in vivo gene expression.

The significant increase in male copulatory behaviors (and in the aromatase protein) in ASSC birds was correlated with and probably caused by a significant increase in the SRC-1 protein above levels observed in control subjects (Fig. $2 B$ ) because such behavioral changes are normally never observed in testosteronetreated castrated quail once they have reached their maximal activity (see above). This compensatory upregulation of the protein in response to the ODN knock-down may reflect the interruption of some sort of negative feedback of the SRC-1 protein on the mRNA expression. As a result of antisense administration, untranslated SRC-1 mRNA may have accumulated [antisense oligonucleotides are supposed to increase RNase $\mathrm{H}$ activity that would counteract this effect, but this enzyme is apparently not expressed at detectable levels and unlikely to play a major role in the brain (Sawai et al., 1977; Landgraf et al., 1997)], and, with the cessation of the treatment, this accumulated message was translated and resulted in the detected increase in the protein. Feedback loops of this sort between message expression and the protein are common in many vertebrate and invertebrate systems (Han et al., 1999; Allada et al., 2001; Venkatesh et al., 2004).

One surprising consequence of this upregulation of the SRC-1 protein was the pronounced increase in the volume of the POM within $2 \mathrm{~d}$ (Fig. 4). There are few examples of sex differences in brain nuclei that are maintained by steroid action in adulthood. Only one example is known in mammalian species, the posterodorsal nucleus of the medial amygdala, in which a sex difference in volume was reported by Cooke et al. (1999) that was decreased by castration and restored by testosterone treatment. In some songbird species, vocal control nuclei such as the high vocal center (HVC) change seasonally in volume under the influence of variations in plasma concentrations of testosterone (Nottebohm, 1981). These nuclei are also different in males and females, and adult treatment with testosterone increases the volume of HVC in females (Nottebohm, 1980). In quail, the POM volume is larger in males than in females, and this sex difference is maintained by activational effects of testosterone in males. Castration reduces the volume in males to female-typical levels, and testosterone restores this to a male-typical size (Panzica et al., 1996a). In all of these studies to date, the time course of action of testosterone on such sex differences was assumed to be in the order of at least a few weeks. In songbirds, the suggestion has been made that testosterone can act within 1 week (Bernard et al., 1997; Tramontin et al., 2000). We found here that there was a $65 \%$ increase in POM volume within $2 \mathrm{~d}$ of the cessation of a treatment that blocked steroid action. Thus, the time course of the effects of steroids on marked histological sex differences in the brain is more rapid than previously suspected. Previous work based on a longer time course of steroid hormone administration indicated that these effects of testosterone on POM nucleus volume resulted from steroid effects on such cellular attributes as somal size, cell spacing, and neuropil volume (Panzica et al., $1996 a, b)$. It is not known at present whether the more rapid effects induced by the manipulation of steroid action that we observed here involve the same cellular changes.

Steroid hormone effects on brain and behavior are primarily mediated by the hormone binding to an intracellular receptor that results in an upregulation of gene transcription, which results in the implementation of the biological response (Pfaff, 1999). However, in several situations, variation in peripheral concentrations of steroid hormones do not explain variation in the behavioral response to hormones [e.g., individual and sex differences (Grunt and Young, 1952; Balthazart et al., 1996b)]. To understand the actions of sex steroid hormones on reproductive behaviors, one must take into account variation in the responsiveness of the target tissue to the hormone. Investigations of the distribution of sex steroid receptors have identified brain sites related to the activation of reproductive behaviors. Few studies have been able to correlate the behavioral effectiveness of steroid hormones with the concentration of their receptors in a particular brain area (Clark et al., 1985; Balthazart et al., 1996b). Variation in the efficiency of steroid-metabolizing enzymes or in the availability of steroid receptors has also been implicated in some cases (Dessi-Fulgheri et al., 1976; Balthazart et al., 2004). The findings described in this paper indicate that coactivators such as SRC-1 represent another class of proteins that are important for regulating steroid action in adulthood on brain and behavior. We already know that its expression is not constitutive but rather is regulated by a variety of factors, including sex steroid hormones and stress (Bousios et al., 2001; Charlier et al., 2004). It remains to be seen to what extent natural variation in this protein can explain intra-specific variation in the effects of sex steroids on sexual behavior.

\section{References}

Absil P, Baillien M, Ball GF, Panzica G, Balthazart J (2001) The control of preoptic aromatase activity by afferent inputs in Japanese quail. Brain Res Rev 37:38-58.

Absil P, Papello M, Viglietti-Panzica C, Balthazart J, Panzica G (2002a) The medial preoptic nucleus receives vasotocinergic inputs in male quail: a tract-tracing and immunocytochemical study. J Chem Neuroanat 24:27-39. 
Absil P, Braquenier JB, Balthazart J, Ball GF (2002b) Effects of lesions of nucleus taeniae on appetitive and consummatory aspects of male sexual behavior in Japanese quail. Brain Behav Evol 60:13-35.

Adkins EK, Adler NT (1972) Hormonal control of behavior in the Japanese quail. J Comp Physiol Psychol 81:27-36.

Adkins EK, Boop JJ, Koutnik DL, Morris JB, Pniewski EE (1980) Further evidence that androgen aromatization is essential for the activation of copulation in male quail. Physiol Behav 24:441-446.

Allada R, Emery P, Takahashi JS, Rosbash M (2001) Stopping time: the genetics of fly and mouse circadian clocks. Annu Rev Neurosci 24:1091-1119.

Apostolakis EM, Ramamurphy M, Zhou D, Oñate S, O’Malley BW (2002) Acute disruption of select steroid receptor coactivators prevents reproductive behavior in rats and unmasks genetic adaptation in knockout mice. Mol Endocrinol 16:1511-1523.

Aste N, Panzica GC, Viglietti-Panzica C, Harada N, Balthazart J (1998) Distribution and effects of testosterone on aromatase mRNA in the quail forebrain: a non-radioactive in situ hybridization study. J Chem Neuroanat 14:103-115.

Auger AP, Tetel MJ, McCarthy MM (2000) Steroid receptor coactivator-1 (SRC-1) mediates the development of sex-specific brain morphology and behavior. Proc Natl Acad Sci USA 97:7551-7555.

Auger CJ, Bentley GE, Auger AP, Ramamurthy M, Ball GF (2002) Expression of CREB-binding protein in the song control system and hypothalamus of adult Eur starlings (Sturnus vulgaris). J Neuroendocrinol 14:805-813.

Balthazart J, Schumacher M, Ottinger MA (1983) Sexual differences in the Japanese quail: behavior, morphology and intracellular metabolism of testosterone. Gen Comp Endocrinol 51:191-207.

Balthazart J, Libioulle JM, Sante P (1988) Stimulatory effects of the noradrenergic neurotoxin DSP4 on sexual behavior in male quail. Behav Proc $17: 27-44$

Balthazart J, Foidart A, Absil P, Harada N (1996a) Effects of testosterone and its metabolites on aromatase-immunoreactive cells in the quail brain: relationship with the activation of male reproductive behavior. J Steroid Biochem Mol Biol 56:185-200.

Balthazart J, Tlemçani O, Ball GF (1996b) Do sex differences in the brain explain sex differences in the hormonal induction of reproductive behavior? What 25 years of research on the Japanese quail tells us. Horm Behav 30:627-661.

Balthazart J, Absil P, Gérard M, Appeltants D, Ball GF (1998) Appetitive and consummatory male sexual behavior in Japanese quail are differentially regulated by subregions of the preoptic medial nucleus. J Neurosci 18:6512-6527.

Balthazart J, Baillien M, Cornil CA, Ball GF (2004) Preoptic aromatase modulates male sexual behavior: slow and fast mechanisms of action. Physiol Behav 83:247-270.

Baylé JD, Ramade F, Oliver J (1974) Stereotaxic topography of the brain of the quail. J Physiol (Paris) 68:219-241.

Bernard DJ, Wilson FE, Ball GF (1997) Testis-dependent and -independent effects of photoperiod on volumes of song control nuclei in American tree sparrows (Spizella arborea). Brain Res 760:163-169.

Bousios S, Karandrea D, Kittas C, Kitraki E (2001) Effects of gender and stress on the regulation of steroid receptor coactivator-1 expression in the rat brain and pituitary. J Steroid Biochem Mol Biol 78:401-407.

Braasch DA, Corey DR (2001) Locked nucleic acid (LNA): fine-tuning the recognition of DNA and RNA. Chem Biol 8:1-7.

Castagna C, Absil P, Foidart A, Balthazart J (1998) Systemic and intracerebroventricular injections of vasotocin inhibit appetitive and consummatory components of male sexual behavior in Japanese quail. Behav Neurosci 112:233-250.

Charlier TD, Lakaye B, Ball GF, Balthazart J (2002) Steroid receptor coactivator SRC-1 exhibits high expression in steroid-sensitive brain areas regulating reproductive behavior in the quail brain. Neuroendocrinology 76:297-315.

Charlier TD, Ball G, Balthazart J (2004) Plasticity in the expression of the steroid receptor coactivator SRC-1 in quail. Soc Neurosci Abstr 30:440.4.

Clark AS, Davis LA, Roy EJ (1985) A possible physiological basis for the dud-stud phenomenon. Horm Behav 19:227-230.

Cooke BM, Tabibnia G, Breedlove SM (1999) A brain sexual dimorphism controlled by circulating androgens. Proc Natl Acad Sci USA 96:7538-7540.
Delville Y, Hendrick JC, Sulon J, Balthazart J (1984) Testosterone metabolism and testosterone-dependent characteristics in Japanese quail. Physiol Behav 33:817-823.

Dermon CR, Stamatakis A, Tlemçani O, Balthazart J (1999) Performance of appetitive or consummatory components of male sexual behavior is mediated by different brain areas: a 2-deoxyglucose autoradiographic study. Neuroscience 94:1261-1277.

Desjardins C, Turek FW (1977) Effects of testosterone on spermatogenesis and luteinizing hormone release in Japanese quail. Gen Comp Endocrinol 33:293-303.

Dessi-Fulgheri F, Lucarini N, Lupo di Prisco C (1976) Relationships between testosterone metabolism in the brain, other endocrine variables and intermale aggression in mice. Aggress Behav 2:223-231.

Dziuk PJ, Cook B (1966) Passage of steroids through silicone rubber. Endocrinology 78:208-211.

Foidart A, Reid J, Absil P, Yoshimura N, Harada N, Balthazart J (1995) Critical re-examination of the distribution of aromatase-immunoreactive cells in the quail forebrain using antibodies raised against human placental aromatase and against the recombinant quail, mouse or human enzyme. J Chem Neuroanat 8:267-282.

Grunt JA, Young WC (1952) Differential reactivity of individuals and the response of the male guinea pig to testosterone propionate. Endocrinology 51:237-248.

Han Y, Meng T, Murray NR, Fields AP, Brasier AR (1999) Interleukin-1induced nuclear factor- $\kappa \mathrm{B}-\mathrm{I} \kappa \mathrm{B} \alpha$ autoregulatory feedback loop in hepatocytes. J Biol Chem 274:939-947.

Koshkin AA, Singh SK, Nielsen P, Rawanshi VK, Kumar R, Meldgaard M, Olsen CE, Wengel J (1998) LNA (locked nucleic acid): synthesis of the adenine, cytosine, guanine, 5-methylcytosine, thymine and uracil bicyclonucleoside monomers, oligomerisation, and unprecedented nucleic acid recognition. Tetrahedron 54:3607-3630.

Kurreck J, Wyszko E, Gillen C, Erdmann VA (2002) Design of antisense oligonucleotides stabilized by locked nucleic acids. Nucleic Acid Res 30:1911-1918.

Laemmli UK (1970) Cleavage of structural proteins during the assembly of the head of bacteriophage T4. Nature 227:680-685.

Landgraf R, Naruo T, Vecsernyes M, Neumann I (1997) Neuroendocrine and behavioral effects of antisense oligonucleotides. Eur J Endocrinol 137:326-335.

McKenna NJ, O’Malley BW (2002) Combinatorial control of gene expression by nuclear receptors and coregulators. Cell 108:465-474.

McKenna NJ, Lanz B, O’Malley BW (1999) Nuclear receptor coregulators: cellular and molecular biology. Endocrine Rev 20:321-344.

Meijer OC, Steenbergen PJ, De Kloet ER (2000) Differential expression and regional distribution of steroid receptor coactivor SRC-1 and SRC-2 in the brain and pituitary. Endocrinology 141:2192-2199.

Misiti S, Shomburg L, Yen PM, Chin WW (1998) Expression and hormonal regulation of coactivator and corepressor genes. Endocrinology 139:2493-2500.

Molenda HA, Griffin AL, Auger AP, McCarthy MM, Tetel MJ (2002) Nuclear receptor coactivators modulate hormone-dependent gene expression in brain and female reproductive behavior. Endocrinology 143:436-444.

Mong JA, Devidze N, Goodwillie A, Pfaff DW (2003) Reduction of lipocalin-type prostaglandin D synthase in the preoptic area in female mice mimics estradiol effects on arousal and sexual behavior. Proc Natl Acad Sci USA 100:15206-15211.

Monks DA, Xu JM, O’Malley BW, Jordan CL (2003) Steroid receptor coactivator-1 is not required for androgen-mediated sexual differentiation of spinal motoneurons. Neuroendocrinology 78:45-51.

Nottebohm F (1980) Testosterone triggers growth of brain vocal control nuclei in adult female canaries. Brain Res 189:429-436.

Nottebohm F (1981) A brain for all seasons: cyclical anatomical changes in song-control nuclei of the canary brain. Science 214:1368-1370.

Panzica GC, Viglietti-Panzica C, Calcagni M, Anselmetti GC, Schumacher M, Balthazart J (1987) Sexual differentiation and hormonal control of the sexually dimorphic preoptic medial nucleus in quail. Brain Res 416:59-68.

Panzica GC, Viglietti-Panzica C, Balthazart J (1996a) The sexually dimorphic medial preoptic nucleus of quail: a key brain area mediating steroid action on male sexual behavior. Front Neuroendocrinol 17:51-125.

Panzica GC, Castagna C, Aste N, Viglietti-Panzica C, Balthazart J (1996b) 
Testosterone effects on the neuronal ultrastructure in the medial preoptic nucleus of male Japanese quail. Brain Res Bull 39:281-292.

Panzica G, Aste N, Castagna C, Viglietti-Panzica C, Balthazart J (2001) Steroid-induced plasticity in the sexually dimorphic vasotocinergic innervation of the avian brain: behavioral implications. Brain Res Rev $37: 178-200$.

Pfaff D (1999) Drive: neural and molecular mechanisms for sexual motivation. Cambridge, MA: MIT.

Roselli CE, Larkin K, Resko JA, Stellflug JN, Stormshak F (2004) The volume of a sexually dimorphic nucleus in the ovine medial preoptic area/anterior hypothalamus varies with sexual partner preference. Endocrinology 145:478-483.

Sachs BD (1967) Photoperiodic control of the cloacal gland of the Japanese quail. Science 157:201-203.

Sawai Y, Sawasaki Y, Tsukada K (1977) Ribonuclease H activity in the developing rat brain. Life Sci 21:1351-1356.

Schumacher M, Balthazart J (1983) The effects of testosterone and its metabolites on sexual behavior and morphology in male and female Japanese quail. Physiol Behav 30:335-339.

Schumacher M, Balthazart J (1984) The postnatal demasculinization of sexual behavior in the Japanese quail. Horm Behav 18:298-312.

Singh SK, Nielsen P, Koshkin AA, Wengel J (1998) LNA (locked nucleic acid): synthesis and high-affinity nucleic acid recognition. Chem Commun 4:455-456.

Stratton LG, Ewing LL, Desjardins C (1973) Efficacy of testosterone-filled polymethylsiloxane in maintaining plasma testosterone in rabbits. J Reprod Fertil 35:235-244.

Tlemçani O, Ball GF, D’Hondt E, Vandesande F, Sharp PJ, Balthazart J (2000) Fos induction in the Japanese quail brain after expression of appetitive and consummatory aspects of male sexual behavior. Brain Res Bull 52:249-262.

Tramontin AD, Hartman VN, Brenowitz EA (2000) Breeding conditions induce rapid and sequential growth in adult song control circuits: a model of seasonal plasticity in the brain. J Neurosci 20:854-861.

Venkatesh KV, Bhartiya S, Ruhela A (2004) Multiple feedback loops are key to a robust dynamic performance of tryptophan regulation in Escherichia coli. FEBS Lett 563:234-240.

Viglietti-Panzica C, Panzica GC, Fiori MG, Calcagni M, Anselmetti GC, Balthazart J (1986) A sexually dimorphic nucleus in the quail preoptic area. Neurosci Lett 64:129-134.

Viglietti-Panzica C, Balthazart J, Plumari L, Fratesi S, Absil P, Panzica GC (2001) Estradiol mediates effects of testosterone on vasotocin immunoreactivity in the adult quail brain. Horm Behav 40:445-461.

Wahlstedt C, Salmi P, Good L, Kela J, Johnsson T, Hokfelt T, Broberger C, Porreca F, Lai J, Ren K, Ossipov M, Koshkin A, Jakobsen N, Skouv J, Oerum H, Jacobsen MH, Wengel J (2000) Potent and nontoxic antisense oligonucleotides containing Locked nucleic acid. Proc Natl Acad Sci USA 97:5633-5638. 